\title{
Ecological thresholds in marine communities: theory, experiments and management
}

\author{
Richard W. Osman ${ }^{1}$, Pablo Munguia ${ }^{2}$, Roman N. Zajac ${ }^{3}$ \\ ${ }^{1}$ Smithsonian Environmental Research Center, 647 Contees Wharf Road, Edgewater, Maryland 21037-0028, USA \\ ${ }^{2}$ Marine Science Institute, The University of Texas at Austin, 750 Channel View Dr., Port Aransas, Texas 78373, USA \\ ${ }^{3}$ Department of Biology and Environmental Science, University of New Haven, West Haven, Connecticut 06516, USA
}

\begin{abstract}
There is increasing interest in the resilience of marine and estuarine populations, communities and ecosystems, and their rapid change when stresses reach some threshold or tipping point. Current research on thresholds is altering our understanding of these systems, the processes by which they change, and our approach to their management and restoration. In this Theme Section conceptual, modeling, and empirical studies explore threshold dynamics in marine coastal systems in a variety of habitats and across different scales. The contributions provide a window on present research, highlight some of the issues being debated, and point to some of the potential applications of threshold dynamics to resource management issues.
\end{abstract}

KEY WORDS: Thresholds $\cdot$ Resilience $\cdot$ Multiple stable states $\cdot$ Tipping points $\cdot$ Management

Thresholds within ecological systems are the tippingor break-points beyond which rapid state or regime shifts occur (Scheffer et al. 2001, Scheffer \& Carpenter 2003, May et al. 2008). Threshold dynamics are closely tied to the concepts of system resilience or resistance to change resulting from environmental perturbations (e.g. Pimm 1984, O'Neill et al. 1986, Tilman \& Downing 1994, Thrush et al. 2009) and the existence of alternate system states (e.g. Holling 1973, Sutherland 1974, 1990, Folke et al. 2004). All systems are resilient to stress, but at some point stressors will be of sufficient magnitude or persistence to cause dramatic change. If a threshold is crossed, then the original configuration of the system will be displaced by a new configuration with its own resilience and resistance to change. A reduction in stress or a return to the previous environmental conditions may be insufficient to overcome the resilience of the new state and return the system to its previous state. Systems that experience threshold dynamics differ from systems which change incrementally with increases or decreases in stress; management and restoration of ecosystems depend on recognizing and incorporating this difference (Suding et al. 2004, Suding \& Hobbs 2009, Thrush \& Dayton 2010). The present Theme Section (TS) illustrates the variety of theoretical, experimental and applied research into the threshold ecology of marine and estuarine systems.

The concept of a community existing in alternate states with potential thresholds between them has a rich history (e.g. Holling 1973, Sutherland 1974, Pimm 1984, O'Neill et al. 1986). Dramatic, rapid, and unexplained shifts in populations, communities and ecosystems observed in recent years have resulted in an increased interest in both the theory and its application. The existence of distinct multiple states has been documented in marine and estuarine habitats such as coral reefs (e.g. Knowlton 1992, Mumby et al. 2007), fouling communities (Sutherland 1974, 1990), pelagic ecosystems (Litzow \& Ciannelli 2007, Casini et al. 2009), the rocky intertidal (Petraitis \& Latham 1999, Petraitis \& Dudgeon 2004, Petraitis et al. 2009), benthic communities (Peterson 1984, Thrush \& Dayton 2002), kelp forests (Steneck et al. 2002, Konar \& Estes 2003), seagrasses (Worm et al. 1999), and coastal wetlands (Lindig-Cisneros et al. 2003). Coupled with this increasing interest is a debate about the stability of these multiple states (Connell \& Sousa 1983) and the evidence needed to document their existence (Peterson 1984, Petraitis \& Dudgeon 2004). This debate highlights the difficulties in identifying different states, determining their stability and whether they are truly 
alternates of the same system, identifying the environmental conditions that link them and whether transition points are thresholds, and how the temporal aspects of threshold transitions interact with the spatial aspects of multiple states (e.g. metapopulations, metacommunities, landscapes). Given that the existence of multiple states, thresholds, regime shifts, tipping- and break-points are considered in ecosystem management (e.g. Gunderson 1999, Thrush \& Dayton 2002, Lindig-Cisneros et al. 2003, Folke et al. 2004, Suding et al. 2004, Marten 2005, Fischer et al. 2009, Suding \& Hobbs 2009), it is timely to explore the diverse views on thresholds in marine systems.

This TS presents a broad spectrum of research focusing on thresholds within marine and estuarine systems. We identified and contacted many marine ecologists researching into thresholds and solicited from them additional colleagues who might be able to contribute to this TS. Our search likely missed potential contributors and many of those contacted were unable to contribute. The contributions received include both theoretical approaches and empirical examinations of specific systems. A secondary goal was to examine applications to resource management and how threshold systems affect management approaches. We specifically asked the contributors to address this issue.

Several sub-themes emerged from the papers within this TS.

Habitat diversity: The studies represented a diversity of habitats, ranging from the pelagic (Casini et al. 2010) to subtidal sedimentary (Norkko et al. 2010), coral (Dudgeon et al. 2010) and biogenic (Lundquist et al. 2010) reef, and fouling communities (Osman et al. 2010, Munguia et al. 2010), to intertidal populations and communities (Hewitt \& Thrush 2010), and large estuarine ecosystems (Fairweather \& Lester 2010).

Conceptual issues: Petraitis \& Hoffman (2010) examined the concept of thresholds in multiple stable states and some of the confusion that results from different interpretations of 'threshold'. Dudgeon et al. (2010) explored the differences between multiple states and phase shifts as applied to coral reef communities.

Modeling approaches: Several studies used modeling to examine the contributions of various processes to thresholds in marine and estuarine systems. Simple Lotka-Volterra models were used to demonstrate how thresholds and different states can occur in linear systems (Petraitis \& Hoffman 2010) and how the dominance of species with different life histories in a system can be affected by local and regional scales of disturbance (Munguia et al. 2010). Lundquist et al. (2010) used a spatially-explicit patch-dynamics model to explore the effects of temporal and spatial rates of disturbance on a benthic community. They associated disturbance effects with inter-patch connectivity, and showed that as dispersal limitation increases, the tol- erance threshold for dominant species shifts. Fairweather \& Lester (2010) used a state-and-transition model with states defined by biota and transitions by a classification and regression tree (CART) of environmental data to understand the thresholds within an estuarine ecosystem and predict future ecological outcomes of management decisions.

Long-term data sets: These are highlighted in 3 studies. Casini et al. (2010) used a 30 yr data set to examine threshold dynamics in population processes. For Baltic herring they show that a shift in sprat abundance above a threshold level decouples herring growth from salinity, contributing to declines in spawning stock. Hewitt \& Thrush (2010) analyzed a 20 yr data set for an intertidal sand flat to test 2 indicators of regime shifts, changes in abundance of key species and increased temporal variability, both of which were found to precede a shift to an alternate community type with changes in functional and trophic characteristics. Osman et al. (2010) used the results of studies on fouling communities conducted over $20 \mathrm{yr}$ to examine transitions among 4 different community states.

Experimental approaches: Experimental tests of threshold processes are also represented. Norkko et al. (2010) present results from a set of experimental manipulations that assessed the effects of increasing spatial scale of disturbance and differences in environmental context on the recolonization and recovery of benthic fauna, how these may indicate threshold responses, and the implications for understanding regime shifts in species-poor and in more diverse systems. Experimental studies on the effects of predators, temperature, and recruitment were critical to defining the threshold dynamics in the fouling communities examined by Osman et al. (2010).

Management implications: Several studies focused on management concerns. Fairweather \& Lester (2010) examined water management in an estuary to provide better predictions and a foundation from which to evaluate management decisions. Casini et al. (2010) looked at the herring fishery and its management. Hewitt \& Thrush (2010) examined intertidal stressors within a harbor, many of which are linked to human impacts that can be managed. For example, a system shift may have been produced by a relatively small change in sewage disposal interacting with climate dynamics, and their effects on a habitat-forming key species in the system.

These and preceding studies show that threshold dynamics can be complicated and difficult to define. The differences in thinking over what constitutes thresholds, their relationship to multiple stable states, how they are measured, and the implications for management will continue to be debated. This TS provides a focus for future research and discussion. 


\section{LITERATURE CITED}

Casini M, Hjelm J, Molinero JC, Lövgren J and others (2009) Trophic cascades promote threshold-like shifts in pelagic marine ecosystems. Proc Natl Acad Sci USA 106:197-202

Casini M, Bartolino V, Molinero JC, Kornilovs G (2010) Linking fisheries, trophic interactions and climate: threshold dynamics drive herring Clupea harengus growth in the central Baltic Sea. Mar Ecol Prog Ser 413:241-252

Connell JH, Sousa WP (1983) On the evidence needed to judge ecological stability and persistence. Am Nat 121: 789-824

> Dudgeon SR, Aronson RB, Bruno JF, Precht WF (2010) Phase shifts and stable states on coral reefs. Mar Ecol Prog Ser 413:201-216

Fairweather PG, Lester RE (2010) Predicting future ecological degradation based on modelled thresholds. Mar Ecol Prog Ser 413:291-304

Fischer J, Peterson GD, Gardner TA, Gordon LJ and others (2009) Integrating resilience thinking and optimisation for conservation. Trends Ecol Evol 24:549-554

Folke C, Carpenter S, Walker B, Scheffer M, Elmqvist T, Gunderson L, Holling CS (2004) Regmie shifts, resilience, and biodiversity in ecosystem management. Annu Rev Ecol Evol Syst 35:557-581

Gunderson L (1999) Resilience, flexibility and adaptive management-antidotes for spurious certitude? Conserv Ecol $3: 7$

$>$ Hewitt JE, Thrush SF (2010) Empirical evidence of an approaching alternate state produced by intrinsic community dynamics, climatic variability and management actions. Mar Ecol Prog Ser 413:267-276

Holling CS (1973) Resilience and stability of ecological systems. Annu Rev Ecol Syst 4:1-23

Knowlton N (1992) Thresholds and multiple stable states in coral reef community dynamics. Am Zool 32:674-682

Konar B, Estes JA (2003) The stability of boundary regions between kelp beds and deforested areas. Ecology 84: $174-185$

Lindig-Cisneros R, Desmond J, Boyer KE, Zedler JB (2003) Wetland restoration thresholds: Can a degradation transition be reversed with increased effort? Ecol Appl 13: 193-205

Litzow MA, Ciannelli L (2007) Oscillating trophic control induces community reorganization in a marine ecosystem. Ecol Lett 10:1124-1134

Lundquist CJ, Thrush SF, Coco G, Hewitt JE (2010) Interactions between disturbance and dispersal reduce persistence thresholds in a benthic community. Mar Ecol Prog Ser 413:217-228

Marten GG (2005) Environmental tipping points: a new paradigm for restoring ecological security. J Policy Stud 20: 75-87

> May RM, Levin SA, Sugihara G (2008) Complex systems: ecology for bankers. Nature 451:893-895

Mumby PJ, Hastings A, Edwards HJ (2007) Thresholds and the resilience of Caribbean coral reefs. Nature 450:98-101

Munguia P, Osman RW, Hamilton J, Whitlatch RB, Zajac RN (2010) Modeling of priority effects and species dominance in Long Island Sound benthic communities. Mar Ecol Prog Ser 413:229-240

Norkko J, Norkko A, Thrush SF, Valanko S, Suurkuukka H (2010) Shifting patterns of resource utilization in soft- sediment communities - conditional responses to increasing scales of disturbance. Mar Ecol Prog Ser 413:253-266

O'Neill RV, DeAngelis DL, Waide JB, Allen TFH (1986) A hierarchical concept of ecosystems. Princeton University Press, Princeton, NJ

Osman RW, Munguia P, Whitlatch RB, Zajac RN Hamilton J (2010) Thresholds and multiple community states in marine fouling communities: integrating natural history with management strategies. Mar Ecol Prog Ser 413: $277-289$

Peterson CH (1984) Does a rigorous criterion for environmental identity preclude the existence of multiple stable points? Am Nat 124:127-133

> Petraitis PS, Dudgeon SR (2004) Detection of alternative stable states in marine communities. J Exp Mar Biol Ecol 300:343-371

Petraitis PS, Hoffman C (2010) Multiple stable states and relationship between thresholds in processes and states. Mar Ecol Prog Ser 413:189-200

Petraitis PS, Latham RE (1999) The importance of scale in testing the origins of alternative community states. Ecology 80:429-442

> Petraitis PS, Methratta ET, Rhile EC, Vidargas NA, Dudgeon SR (2009) Experimental confirmation of multiple community states in a marine ecosystem. Oecologia 161:139-148

Pimm SL (1984) The complexity and stability of ecosystems. Nature 307:321-326

Scheffer M, Carpenter SR (2003) Catastrophic regime shifts in ecosystems: linking theory to observation. Trends Ecol Evol 18:648-656

Scheffer M, Carpenter S, Foley J, Folke C, Walker B (2001) Catastrophic shifts in ecosystems. Nature 413:591-596

Steneck RS, Graham MH, Bourque BJ, Corbett D, Erlandson JM, Estes JA, Tegner MJ (2002) Kelp forest ecosystems: biodiversity, stability, resilience and future. Environ Conserv 29:436-459

Suding KN, Hobbs RJ (2009) Threshold models in restoration and conservation: a developing framework. Trends Ecol Evol 24:271-279

Suding KN, Gross KL, Houseman GR (2004) Alternative states and positive feedbacks in restoration ecology. Trends Ecol Evol 19:46-53

Sutherland JP (1974) Multiple stable points in natural communities. Am Nat 108:859-873

- Sutherland JP (1990) Perturbation, resistance, and alternative views of the existence of multiple stable points in nature. Am Nat 136:270-275

- Thrush SF, Dayton PK (2002) Disturbance to marine benthic habitats by trawling and dredging: implications for marine biodiversity. Annu Rev Ecol Syst 33:449-473

Thrush SF, Dayton PK (2010) What can ecology contribute to ecosystem-based management? Annu Rev Mar Sci 2: 419-441

Thrush SF, Hewitt JE, Dayton PK, Coco G and others (2009) Forecasting the limits of resilience: integrating empirical research with theory. Proc R Soc Biol Sci Ser B 276: 3209-3217

Tilman D, Downing JA (1994) Biodiversity and stability in grasslands. Nature 367:363-365

Worm B, Lotze HK, Boström C, Engkvist R, Labanauskas V, Sommer U (1999) Marine diversity shift linked to interactions among grazers, nutrients and propagule banks. Mar Ecol Prog Ser 185:309-314 